\title{
RESQUÍCIOS DE PADRÕES GEOQUÍMICOS KOMATIÍTICOS EM ROCHAS METAULTRAMÁFICAS DE ALPINÓPOLIS, MINAS GERAIS
}

\author{
G.A.J.Szabó ${ }^{1}$, M.A.F.Candia ${ }^{1}$, A.Choudhuri ${ }^{2}$
}

As rochas metaultramáficas que afloram a S e SW de Alpinópolis (MG) constituem corpos de diversos tamanhos, inseridos no Domínio Norte do Complexo Campos Gerais, que corresponde a terrenos arqueanos tipo granito - greenstone belt intensamente reorganizados ao longo de extensas zonas de cisalhamento. Agrupam-se em duas áreas de ocorrência, correlacionadas à Seqüência Vulcano - Sedimentar Morro do Ferro. $\mathrm{Na}$ área do Ribeirão da Conquista, os ultramafitos são predominantemente variedades de cloritaclinoanfibólio (tremolita a hornblenda) xistos e fels \pm antofilita e/ou olivina. Texturas spinifex pseudomórficas são preservadas em núcleos lenticulares envoltos pela foliação de cisalhamento anastomosada. Na área do Córrego da Mumbuca, a suite ultramáfica apresenta paragêneses de grau metamórfico mais elevado, com olivina e/ou ortopiroxênio + hornblenda \pm espinélio verde e/ou clorita, e não há evidências de feições pré-metamórficas preservadas.

Amostras de clorita-clinoanfibólio fels com texturas spinifex em padrões diversos e tipos petrográficos com olivina e/ou ortopiroxênio + hornblenda \pm espinélio e/ou clorita foram analisadas por FRX para elementos maiores, menores e traço, num total de 31 análises. Elementos Terras Raras (ETR) foram determinados por Ativação Neutrônica em 8 amostras. Na Figura 1, as análises projetadas no diagrama catiônico ( $\left.\mathrm{Fe}_{\text {total }}+\mathrm{Ti}\right)-\mathrm{Al}-\mathrm{Mg}$, ilustram a tendência de variação composicional komatiítica da suite ultramáfica. $\mathrm{Na}$ tentativa de reconhecer conjuntos de amostras que preservassem algo dos antigos padrões geoquímicos komatiíticos, recorreu-se às razões de elementos incompatíveis HFSE, considerados menos móveis: $\mathrm{Ti} / \mathrm{Zr}$, Ti/Sc e $\mathrm{Sc} / \mathrm{Zr}$, complementadas com a razão $\mathrm{Al}_{2} \mathrm{O}_{3} / \mathrm{TiO}_{2}$. Identificou-se um conjunto de 15 amostras para as quais estas razões são constantes, e apresentam um comportamento notadamente regular, concentrando-se em campos restritos, quase pontuais em diagramas binários entre razões elementares (Fig. 2). A razão $\mathrm{Al}_{2} \mathrm{O}_{3} / \mathrm{TiO}_{2}$ deste conjunto "depurado" situa-se em torno de 11 (mínimo 9,9, máximo 13,2, média 11,3), característica dos komatiitos ADK (aluminium depleted komatiites), como os de Barberton. As razões $\mathrm{Ti} / \mathrm{Zr}(\sim 77)$ e Sc/Zr $(\sim 0,74)$ são inferiores aos valores condríticos (respectivamente 115 e 1,6), enquanto a razão Ti/Sc $(\sim 101)$ é superior (valor condrítico 75). Em uma amostra com textura spinifex foram encontrados xenocristais de zircão, sugerindo contaminação crustal, que explicaria os teores de $\mathrm{Zr}$ mais elevados. O Sc é relativamente empobrecido: nos komatiitos tipo ADK, Al e o Sc são retidos na fonte, provavelmente por fracionamento de granada. A combinação destes dois fatores pode explicar as razões não-condríticas mencionadas, com diferença proporcionalmente maior para o $\mathrm{Sc} / \mathrm{Zr}$, onde se combinam o empobrecimento em Sc e o enriquecimento em $\mathrm{Zr}$. As razões $\mathrm{CaO} / \mathrm{Al}_{2} \mathrm{O}_{3}$ são sistematicamente superiores a 1 , outra característica dos komatítos tipo ADK.

\footnotetext{
${ }^{1}$ DMP, Instituto de Geociências, Universidade de São Paulo.
}

${ }^{2}$ Instituto de Geociências, Universidade Estadual de Campinas. 


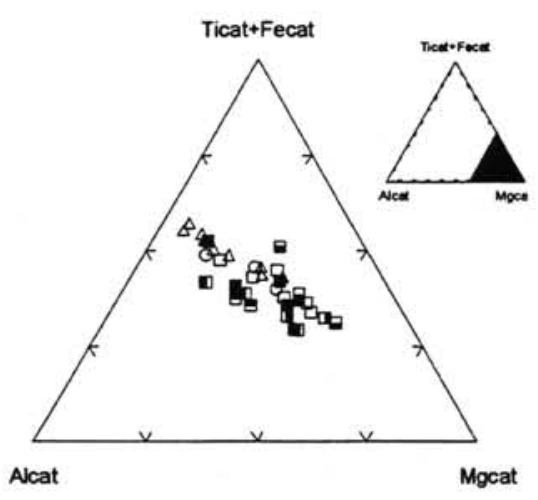

Figura 1 - Diagrama catiônico (Fe+Ti)-Al-Mg para a suíte metaultramáfica de Alpinópolis (MG). Em destaque o campo dos komatiitos.

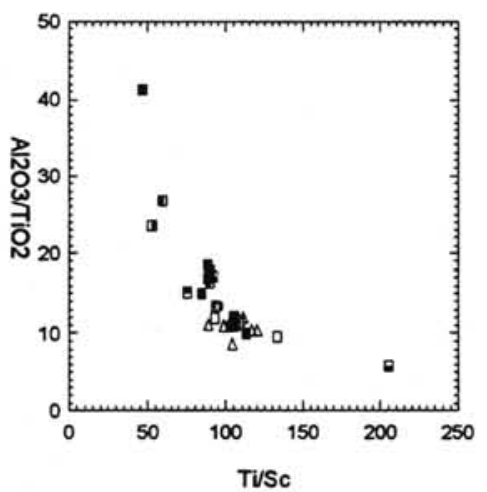

Figura 2 - Diagrama $\mathrm{Al}_{2} \mathrm{O}_{3} / \mathrm{TiO}_{2} \mathrm{X} \mathrm{Ti} / \mathrm{Sc}$. Em torno do ponto $\mathrm{Al}_{2} \mathrm{O}_{3} / \mathrm{TiO}_{2}=11, \mathrm{Ti} / \mathrm{Sc}=100$ concentram-se 15 análises. Total: 31 análises.

Os padrões de ETR são pouco convencionais: amostras com textura spinifex (Fig. 3) exibem enriquecimento exagerado em ETR leves ( $\mathrm{LaN} / \mathrm{SmN}>3)$, alcançando valores superiores a $100 \mathrm{X}$ Condrito para o $\mathrm{La}$, e menos pronunciados para o $\mathrm{Ce}$ (em torno de 15 a $20 \mathrm{X}$ Condrito), que se apresenta então como uma anomalia negativa aparente. Nas demais amostras (Fig. 4), os padrões de ETR são relativamente mais planos (LaN/SmN entre 1,2 e 1,9 e $\mathrm{GdN} / \mathrm{YbN}$ entre 0,97 e 1,12); da ordem de 2 a $10 \mathrm{X}$ Condrito. $\mathrm{O}$ enriquecimento em $\mathrm{La}, \mathrm{Ce}$ e $\mathrm{Nd}$ é acompanhado pelo Y. A combinação destes fatores, incluindo o enriquecimento diferenciado, menos pronunciado em $\mathrm{Ce}$, e o fato dos padrões ETR fortemente fracionados ocorrerem tipicamente em rochas provenientes das porções superiores de derrames estratificados, sugere modificações químicas seletivas, mais provavelmente decorrentes de alteração tardi-pós magmática parcial, localizada, em ambiente sub-aquático marinho, a temperaturas não superiores a $100^{\circ} \mathrm{C}$ (e.g. Ludden \& Thompson, 1978; Condie, 1989), que não afetaram significativamente o Ti, Sc e Zr. 


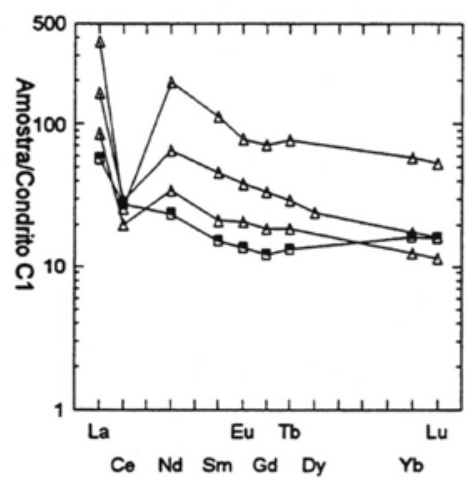

Figura 3 - Padrões de ETR para amostras com enriquecimento pronunciado em ETR leves.

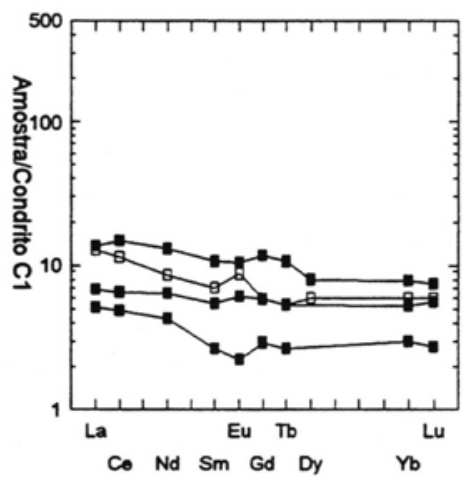

Figura 4 - Padrões de ETR relativamente mais planos, com enriquecimento em ETR leves menos pronunciado.

\section{Referências Bibliográficas}

CONDIE, K.C. (1989) Plate tectonics and crustal evolution. 3.ed. Oxford, Pergamon, 467p. LUDDEN, J.N.; THOMPSON, G. (1978) Behaviour of rare earth elements during submarine weathering of tholeiitic basalt. Nature, v.274, n.5667, p.147-149. 